\title{
Residency and movement patterns of Cuvier's beaked whales Ziphius cavirostris off Cape Hatteras, North Carolina, USA
}

\author{
Heather J. Foley ${ }^{1,2, *}$, Krishna Pacifici ${ }^{2}$, Robin W. Baird ${ }^{3}$, Daniel L. Webster ${ }^{3}$, \\ Zachary T. Swaim ${ }^{1}$, Andrew J. Read ${ }^{1}$ \\ ${ }^{1}$ Duke University Marine Laboratory, Duke University, 135 Duke Marine Lab Road, Beaufort, NC 28516, USA \\ ${ }^{2}$ Department of Forestry and Environmental Resources, Program in Fisheries, Wildlife and Conservation Biology, \\ North Carolina State University, Raleigh, NC 27695, USA \\ ${ }^{3}$ Cascadia Research Collective, $2181 / 2$ West $4^{\text {th }}$ Avenue, Olympia, WA 98501, USA
}

\begin{abstract}
Cuvier's beaked whales Ziphius cavirostris are wide-ranging, deep-diving cetaceans that are particularly sensitive to anthropogenic noise. Current stock assessments assume a single population in the western North Atlantic Ocean, but knowledge of the residency patterns and distribution of the species is currently lacking in the region. Here we describe the spatial ecology of 20 Cuvier's beaked whales equipped with satellite-linked tags off Cape Hatteras, North Carolina, USA, between 2014 and 2017. We applied a hierarchical switching state-space model to filter location estimates and define behavioral states of area-restricted search (ARS) and transit. We used kernel density estimation to identify high use areas, and net squared displacement analyses to assess residency. The vast majority ( $96 \%$ ) of locations were classified as ARS behavior, suggesting that tagged whales allocated much of their time to foraging. Maximum net displacement had a sample median of $50 \mathrm{~km}$, and $81 \%$ of individual whales were classified as demonstrating a resident, or 'home range,' movement pattern. Overall, our research indicates a localized population of Cuvier's beaked whales occupying the area off Cape Hatteras. The tagged animals demonstrated a small, defined core use area and exhibited little displacement from the region. These patterns of movement and spatial use can inform future conservation and management of this species, which is vulnerable to anthropogenic disturbances caused by several sources, including mid-frequency active sonar and seismic exploration.
\end{abstract}

KEY WORDS: Cuvier's beaked whale $\cdot$ Ziphius cavirostris $\cdot$ Satellite telemetry $\cdot$ Residency $\cdot$ Site fidelity $\cdot$ Spatial ecology $\cdot$ Biologging $\cdot$ State-space modeling $\cdot$ Net squared displacement

\section{INTRODUCTION}

Cuvier's beaked whales Ziphius cavirostris are cosmopolitan members of the family of beaked whales, Ziphiidae, which frequent shelf edge and continental slope waters (Waring et al. 2001, Tyack et al. 2006). The species is the deepest-diving air-breathing vertebrate, with dives to $3567 \mathrm{~m}$ that can last over $2 \mathrm{~h}$

*Corresponding author: heather.foley@duke.edu
(Schorr et al. 2014, Shearer et al. 2019). Cuvier's beaked whales forage during dives to depths greater than $800 \mathrm{~m}$, each followed by a series of shorter submergences to depths less than $400 \mathrm{~m}$ (Baird et al. 2006, Tyack et al. 2006, Shearer et al. 2019). These animals feed on meso- and bentho-pelagic cephalopods, fish, and crustaceans (Waring et al. 2001, West et al. 2017), and when foraging in slope areas, it is restricted. Authors and original publication must be credited. 
believed that fixed bathymetric features including canyons, shelf edges, and seamounts serve to concentrate and/or aggregate their prey (Moulins et al. 2007, Moors-Murphy 2014). In the western North Atlantic, the species is also found in association with warm-core rings and other ephemeral oceanographic features affiliated with the Gulf Stream, leading to high densities in these areas (Waring et al. 2016).

Due to their response to naval mid-frequency active sonar (MFAS), which has been known to cause mass and single strandings, Cuvier's beaked whales are of particular conservation concern (Cox et al. 2006, D'Amico et al. 2009, Tyack et al. 2011, DeRuiter et al. 2013, Simonis et al. 2020). Behavioral response studies, conducted using controlled exposure experiments (CEEs) in the Bahamas, Norway, and southern California, have demonstrated that the species is particularly sensitive to acoustic disturbance (Southall et al. 2016). During these experiments, focal individuals reacted strongly to simulated sonar signals by interrupting foraging dives and moving away from the sound source, often over tens of kilometers and for several days (Tyack et al. 2011). These substantive behavioral modifications could result in significant fitness costs (Tyack et al. 2011, DeRuiter et al. 2013). Therefore, a better understanding of baseline patterns of movement and foraging ecology of Cuvier's beaked whales could help place these behavioral responses to MFAS within an ecological context, and better define mitigation strategies for acoustic disturbances to the species throughout its range.

Previous studies in the Ligurian Sea, Canary Islands, Hawai'i, and southern California have demonstrated that Cuvier's beaked whale populations exhibit high degrees of site fidelity (McSweeney et al. 2007, Schorr et al. 2014, Falcone et al. 2017, Reyes 2017, Baird 2019). In the western North Atlantic, a single stock is currently recognized for the species (Waring et al. 2016). However, the continental slope waters off Cape Hatteras, North Carolina, USA, appear to be particularly important habitat, with occupancy and site fidelity demonstrated between seasons and years (Forney et al. 2017, Waples \& Read 2020). The species is present in high densities yearround in this area, with substantially fewer visual and acoustic detections in Norfolk Canyon to the north and Onslow Bay to the south (Stanistreet et al. 2017, McLellan et al. 2018).

The western North Atlantic is an increasingly noisy environment (Weilgart 2007, Hildebrand 2009, Stanistreet et al. 2017). Cetaceans in this region must cope with the sounds of shipping traffic, naval exer- cises using MFAS, and potential offshore energy exploration (Schick et al. 2011). Given the particular sensitivity of Cuvier's beaked whales to anthropogenic noise, we wanted to gain a better understanding of the home ranges and spatial use patterns of the species in this region, which is in close proximity to the largest naval base in the world (Norfolk, Virginia), as well as an area where future seismic exploration is likely (Weilgart 2007, Schick et al. 2011, Forney et al. 2017).

Analysis of residency in cetaceans often employs capture-recapture methods based on photo-identification. However, due to the infrequency of sightings of this species, obtaining sufficient photos to examine long-term site fidelity can take many years (e.g. Baird 2019). The use of satellite-linked tags permits tracking of animals over weeks and months, allowing both movement and residency patterns to be analyzed at fine scales (Hussey et al. 2015, Hays et al. 2016). No dedicated studies of the home ranges or movement patterns of Cuvier's beaked whales have been conducted to date in the western North Atlantic.

Here we sought to establish a baseline of the spatial ecology of Cuvier's beaked whales off Cape Hatteras, using data from 20 individuals satellite-tagged between 2014 and 2017. Our primary objective was to establish the geographic range and residency of the population. Based on work conducted in other areas (McSweeney et al. 2007, DeRuiter et al. 2013, Falcone et al. 2017, Baird 2019), we hypothesized that Cuvier's beaked whales would demonstrate high site fidelity to the area and relatively small home range sizes.

\section{MATERIALS AND METHODS}

\subsection{Study area}

The study area includes the outer continental shelf and slope waters off Cape Hatteras, North Carolina, USA (Fig. 1). The continental shelf is relatively narrow at Cape Hatteras, and the slope is quite steep, with depth increasing from 200 to $>1500 \mathrm{~m}$ in less than $10 \mathrm{~km}$ (Mullin \& Fulling 2003). The Gulf Stream is the dominant oceanographic feature in the area, forming the largest frontal system in the North Atlantic (Chambault et al. 2017). The primary study region was 'The Point,' where the Gulf Stream flow peels off the continental shelf, heading northeast into pelagic waters (Forney et al. 2017). 


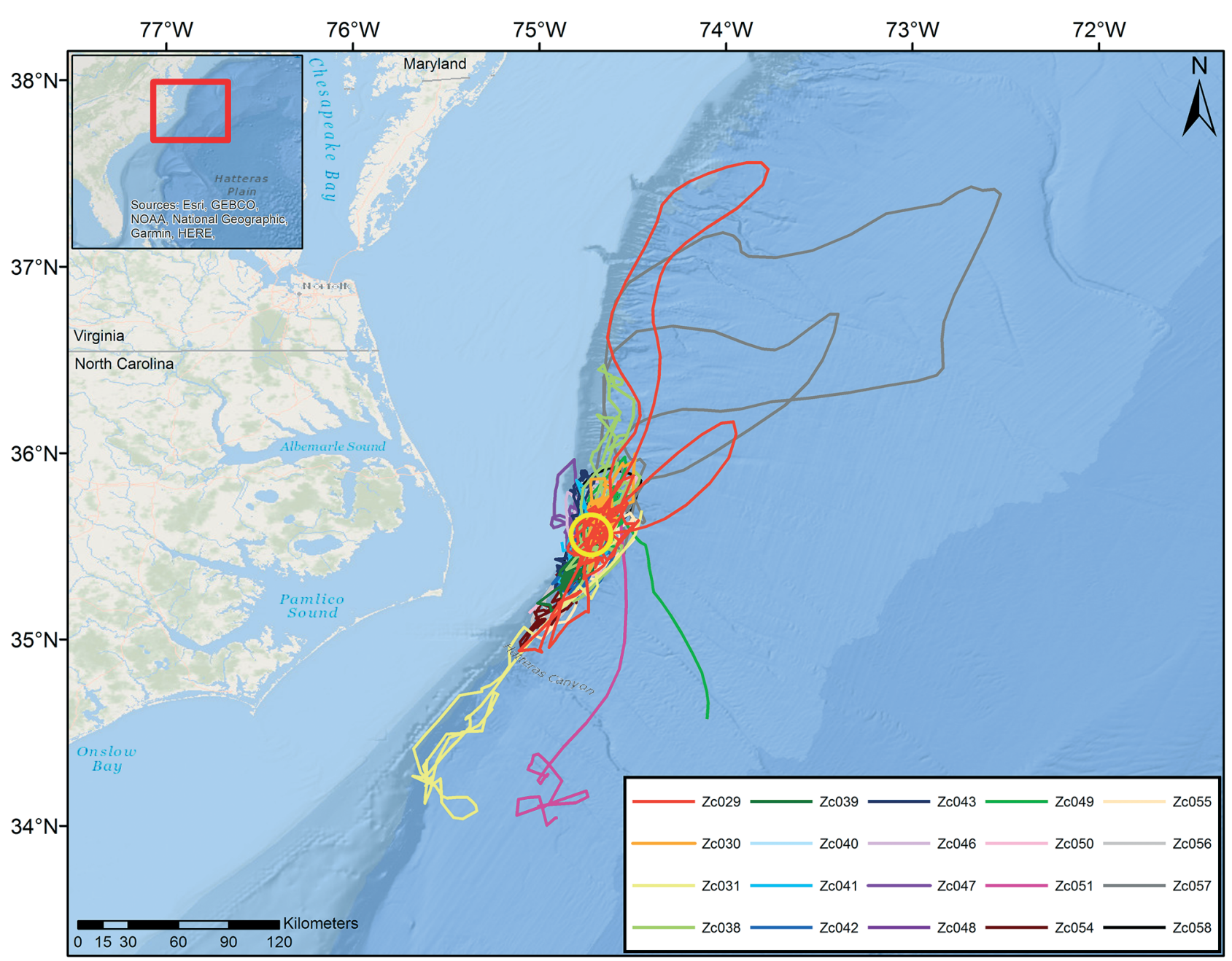

Fig. 1. Individual tracks of Cuvier's beaked whales satellite-tagged between 2014 and 2017 (n = 20; see Table 1) estimated at a $6 \mathrm{~h}$ time step via a hierarchical switching state-space model. Yellow-outlined circle: tagging locations offshore of Cape Hatteras, North Carolina, USA

\subsection{Spatial use}

\subsubsection{Telemetry}

We deployed satellite-linked tags in the Low Impact Minimally Percutaneous External-electronics Transmitter (LIMPET) configuration (Andrews et al. 2008, Baird et al. 2010, 2011a) using a pneumatic rifle from a $9.1 \mathrm{~m}$ aluminum-hulled vessel. The tags were deployed into or just below the dorsal fin of 20 Cuvier's beaked whales between 2014 and 2017. As described by Thorne et al. (2017), the tags were attached using 2 titanium darts $(6.7 \mathrm{~cm})$ with backward facing petals. We attempted to photograph all animals we encountered prior to, during, and post tag deployment for individual identification, as well as sex and age class designation using photo-identi- fication methods detailed by Shearer et al. (2019). We compared photographs across all survey effort in order to catalog each individual and validate all tagged individuals as unique. Most tags $(n=16)$ were Wildlife Computers SPLASH10A satellite-linked depth-recording tags from which both position and compressed dive records are transmitted. Four other animals were equipped with Smart Position and Temperature (SPOT5 \& 6) tags, which provide only the surface location of the animals. Location estimates were derived using a least squares method from Service Argos receivers on polar-orbiting satellites. Transmission schedules varied by deployment year. Tags deployed in 2014-2016 were programmed to initially transmit $18-20 \mathrm{~h} \mathrm{~d}^{-1}$, based on tag type. SPOT5 tags deployed in 2014-2015 transmitted daily for $80 \mathrm{~d}$, followed by every second day for $10 \mathrm{~d}$, 
and every fifth day until transmissions ceased. The SPOT6 tag deployed in 2016 transmitted daily, with the number of transmitting hours per day being reduced to 8 at $80 \mathrm{~d}$. In 2014, SPLASH10A tags transmitted daily for $28 \mathrm{~d}$, and every second day afterwards, and SPLASH10A tags deployed in 2015 and 2016 transmitted every day for $25 d$, then every second day for $8 \mathrm{~d}$, followed by every third day. All tags deployed in 2017 transmitted for $21 \mathrm{~h}$ every day.

All positions were assigned an estimated accuracy location class (LC) based on the timing and number of transmissions received during a satellite pass. LCs 0 to 3 have designated error radii of $>1500$, 500-1500, 250-500, and $<250 \mathrm{~m}$, respectively, and LCs A and B do not have an estimated level of error (Argos 2007-2016). Location class Z positions are considered invalid by Argos and were not included in analyses.

\subsubsection{Location filtering and behavioral state estimation}

We fit a hierarchical Bayesian switching statespace model (hSSSM) (Jonsen et al. 2003, 2005, 2007) using the 'bsam' package v 1.1.2 (Jonsen 2016) at $6 \mathrm{~h}$ time intervals across all individuals in $\mathrm{R}$ version 3.6.0 ( $R$ Development Core Team 2018) to estimate the locations of each animal and distinguish between 2 behavioral states: area-restricted search (ARS) and transit. Two separate first-difference correlated random walks were used in the process model (transition equation), which allowed parameters to vary between 2 distinct behavioral states, while also estimating the location of the animal. The 2 states are defined by mean turning angle and movement persistence of the animal. Hierarchical models can vastly improve behavioral state estimation and increase accuracy of movement parameters by borrowing strength across all tracks (Jonsen 2016), and is particularly suited to data with large location error relative to the scale of movement.

Within the hSSSM, the behavioral state at time $t$ $\left(b_{t}\right)$ is estimated using the mean value from Markov chain Monte Carlo (MCMC) samples, which provide a continuous value from 1 (transit) to 2 (ARS) (Jonsen 2016). After removing any points with duplicate timestamps, we ran the hSSSM with a burn-in of 30000 samples, generating $10000 \mathrm{MCMC}$ samples in each of 2 chains. We retained every $10^{\text {th }}$ sample to reduce within-chain sample autocorrelation (Jonsen 2016), for 2000 final posterior samples which we used to calculate model parameters and estimated loca- tions. Based on the results of previous studies, we considered behavioral state values of $<1.25$ as transit behavior, those $>1.75$ as ARS, and intermediate values between 1.25 and 1.75 as uncertain (Jonsen et al. 2007, Bailey et al. 2009, Kennedy et al. 2014, AcuñaMarrero et al. 2017, Fortune et al. 2020).

ARS is associated with frequent course reversals and relatively slow swim speed, whereas transit behavior has higher rates of movement with increased persistence between locations (Jonsen 2016). Across studies of many different animal taxa, foraging has been inferred from ARS behavior, in which animals slow their horizontal movement speeds and increase turning rates in highly productive areas (Fortune et al. 2020). Animals are believed to spend more time in a particular area if they are foraging successfully (Fortune et al. 2020). It is possible that ARS could include behaviors such as breeding or resting (Bailey et al. 2009). However, the beaked whales tagged in this study consistently dove to depths at which they are known to forage, spending very little time at the surface of the water (Shearer et al. 2019). Previous studies have determined that nonforaging time in Cuvier's beaked whales is spent in: (1) short surfacing bouts of $\sim 2$ min, (2) relatively shallow 'bounce dives,' or (3) transit to and from foraging depths (Barlow et al. 2013, 2020). Thus, taken together, we inferred that ARS of Cuvier's beaked whales demonstrated foraging behavior.

Environmental metrics were calculated at each position of the hSSSM output, including bathymetric depth, slope, distance to shelf break, and sea surface temperature. We used the National Oceanic and Atmospheric Administration National Centers for Environmental Information (NCEI) 3 arc-second Southeast Atlantic US Coastal Relief Model (CRM) to generate depth values whenever possible. In areas not included in the NCEI CRM $(<6 \%$ of locations in this study), we employed 30 arc-second data from the General Bathymetric Chart of the Oceans (GEBCO) 2014 global bathymetry grid (www.gebco. net). We also used the GEBCO bathymetric grid to generate slope values and the $200 \mathrm{~m}$ isobath contour, which served as a proxy for the continental shelf break (Thorne et al. 2017). We obtained Group for High Resolution Sea Surface Temperature (www. ghrsst.org) grids with a $1 \mathrm{~km}$ resolution using the NOAA Coastwatch tool Xtractomatic (http://coast watch.pfeg.noaa.gov/xtracto/) in R (R Development Core Team 2018). In addition, total travel distances, calculated as great circle distances between the hSSSM-estimated locations, and thus representing the absolute minimum horizontal distance tra- 
versed between locations, were calculated for each individual.

\subsubsection{Home range estimation}

To describe spatial use by Cuvier's beaked whales, we evaluated home range and core use areas both for each individual tagged whale and for the sample of all tagged animals using utilization distributions (UDs) generated through kernel density estimation (KDE) from the hSSSM output. We used core use areas to represent particularly high use areas for each individual (Johnston et al. 2005, Hauser et al. 2014). Home range estimation can be sensitive to auto-correlated data, but serial independence of observations is not required (De Solla et al. 1999). Instead, maximizing the number of observations while using regularly spaced time intervals, such as those generated from the hSSSM, leads to more precise and accurate results (De Solla et al. 1999, Fieberg 2007). After the hSSSM-estimated locations were projected to the Albers Equal Area projection, we generated core use (50\% probability contour) and home range ( $95 \%$ probability contour) areas and associated isopleths in the R package 'ks' using the bivariate plug-in bandwidth matrix as the smoothing parameter (Duong \& Hazelton 2003, 2005, Duong 2007). The plug-in bandwidth is a 'second-generation' kernel density estimator allowing for separate bandwidths in the $x$ - and $y$-directions that performs well at identifying high use areas, even with autocorrelated telemetry data (Hall et al. 1995, Jones et al. 1996, Walter et al. 2015). We used linear regression to evaluate the relationship between individual track duration and the areal size of both home range and core use areas.

\subsubsection{Movement patterns}

We calculated net squared displacement (NSD) to evaluate movement patterns of Cuvier's beaked whales offshore of Cape Hatteras. We ran a candidate set of movement pattern models for all tags with $>100$ hSSSM-estimated locations, or approximately $25 \mathrm{~d}$ of tag duration, adapting code from Papworth et al. (2012). NSD, i.e. the Euclidean distance between the initial and subsequent locations of an animal over time, has been used both in marine and terrestrial systems to evaluate movement patterns of individuals (Bunnefeld et al. 2011, Harrison 2012, Papworth et al. 2012). Animal movements lie on a continuum between nomadism, in which an animal never remains in the same place for long periods, and sedentarism, where an animal is spatially constrained within a home range (Börger \& Fryxell 2012). The other two over-arching movement tactics are dispersal and migration. Specific movement patterns are classified to individuals by fitting the NSD curve of an animal to a series of potential non-linear mixed movement models unique to each tactic, linking theoretical expectations in variation to observed NSD (Singh et al. 2012, Couriot et al. 2018). Home range, or resident animals, have either a constant NSD or one whose NSD curve asymptotes following a linear increase. Nomadism is denoted by a continuous, linear increase in NSD over time, while migration models show seasonal departures and return to an initial location, following a plateau. Dispersing animals demonstrate departure from an animal's initial location followed by a plateau, but fail to return (Börger \& Fryxell 2012). The best fitting model and its associated movement pattern category for each individual was assigned using concordance criterion values, with the largest value corresponding to the most appropriate tactic. Random effects were included in models to account for individual variability, in addition to sparse or unbalanced data, but see Börger \& Fryxell (2012) for additional detail on model structure and selection.

We plotted NSD over time for each individual, along with the sample population mean. We calculated maximum net displacement for each individual from their initial location as the maximum value of the square root of each NSD at every subsequent location. To evaluate any linear association between maximum net displacement and individual track duration, we used linear regression.

\section{RESULTS}

\subsection{Spatial use}

We tagged 20 Cuvier's beaked whales between May 2014 and May 2017, with transmissions ranging in duration from 2 to $93 \mathrm{~d}$, with a mean length of $42 \pm 21 \mathrm{~d}$ (SD) (Table 1). Twelve of the animals tagged were adult males, 3 were adult females, 3 were adults of unknown sex, and 2 were animals of unknown sex or age class. No individuals were tagged on more than one occasion. Animals remained in close association with the continental shelf and slope waters, ranging from Onslow Bay in the south to the Virginia/Maryland border to the north (Fig. 1). Fifteen individuals remained 


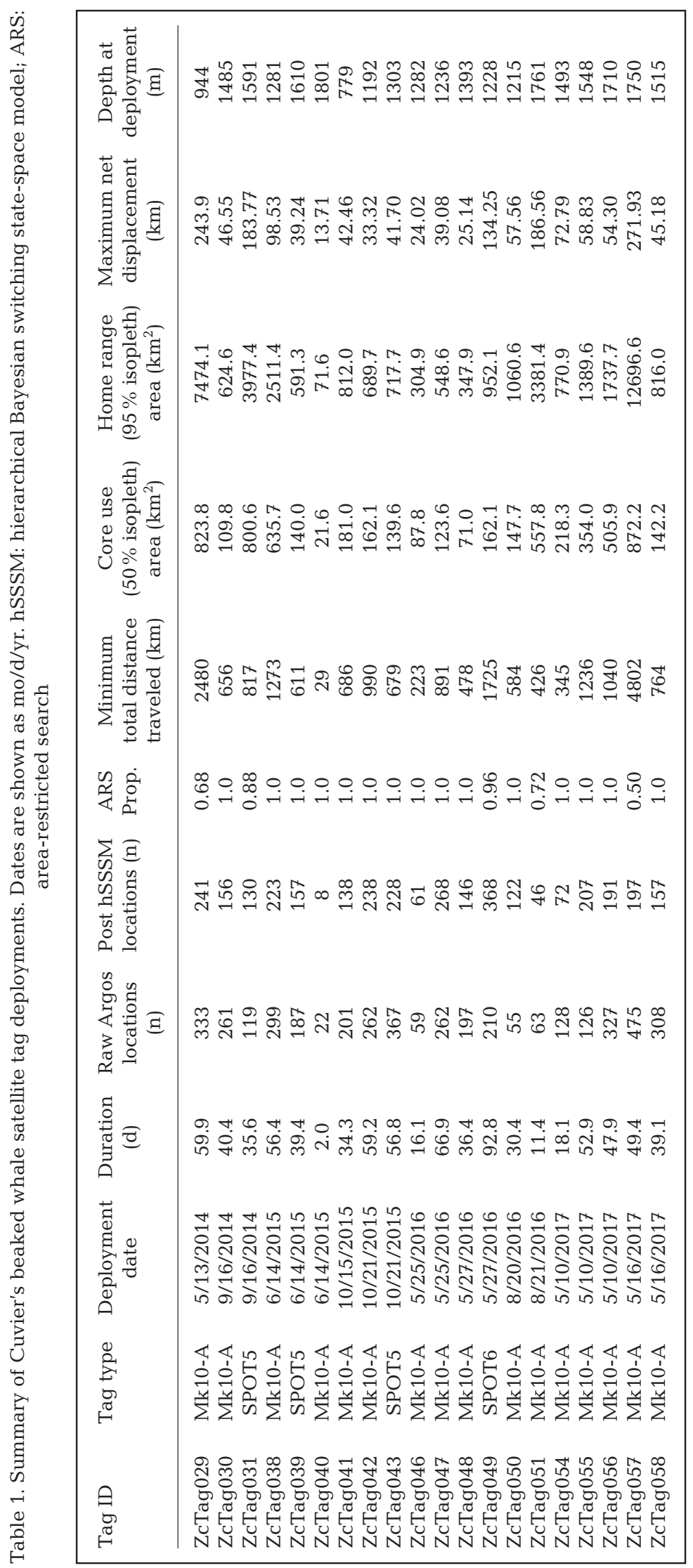

within $100 \mathrm{~km}$ of their tagging locations off Cape Hatteras, and no animal ventured farther than $272 \mathrm{~km}$ from its initial location during its tracking period (Table 1, Fig. 1). Total travel distances ranged from 29 to $4802 \mathrm{~km}$ across individuals. The median water depth at estimated surface locations was $1590 \mathrm{~m}$ $($ mean $\pm \mathrm{SD}=1524 \pm 641 \mathrm{~m}$, range $=$ 47-3662 m). The median distance to the continental shelf break (200 $\mathrm{m}$ isobath) was $10 \mathrm{~km}$ (mean $\pm \mathrm{SD}=13.6 \pm 16.4 \mathrm{~km})$, with a maximum distance from the shelf break of $165 \mathrm{~km}$. Slope at estimated locations had a median value of $4.9^{\circ}$, a mean of $5.7^{\circ}$, and a maximum of $18.6^{\circ}$. Daily sea surface temperature values at estimated locations ranged from 16.1 to $30.4^{\circ} \mathrm{C}$, with a mean of $26.2^{\circ} \mathrm{C}\left(\right.$ median $\left.=26.3^{\circ} \mathrm{C}\right)$.

\subsection{Location filtering and behavioral state estimation}

The hSSSM generated 3354 estimated locations for the 20 individuals and clearly distinguished between transit $(4.8 \%$ of locations) and ARS (93.5\%) behaviors, with only $1.7 \%$ of the points classified as uncertain (Fig. 2). ARS behavior was the dominant mode for most individuals, with most animals $(75 \%)$ remaining in that behavioral mode for the entirety of their tag transmission time (Table 1, Fig. A1a in the Appendix). ARS behavior was more prevalent in locations close to the study site and continental shelf break (mean distance to $200 \mathrm{~m}$ isobath $=11.3 \mathrm{~km}$ ) (Fig. 2), and transit behavior generally occurred when animals departed from the study site, north and east of the shelf break (mean distance to $200 \mathrm{~m}$ isobath $=50.5 \mathrm{~km}$ ) (Fig. A1b).

\subsection{Home range estimation}

The home range area for the sample population ranged from the Virginia/ North Carolina border southward to Onslow Bay, straddling the continental shelf break (Fig. 3). The core use area for the tagged whales comprised a single area of $583 \mathrm{~km}^{2}$ just east of the continental shelf break off Cape Hatteras (Fig. 3). 


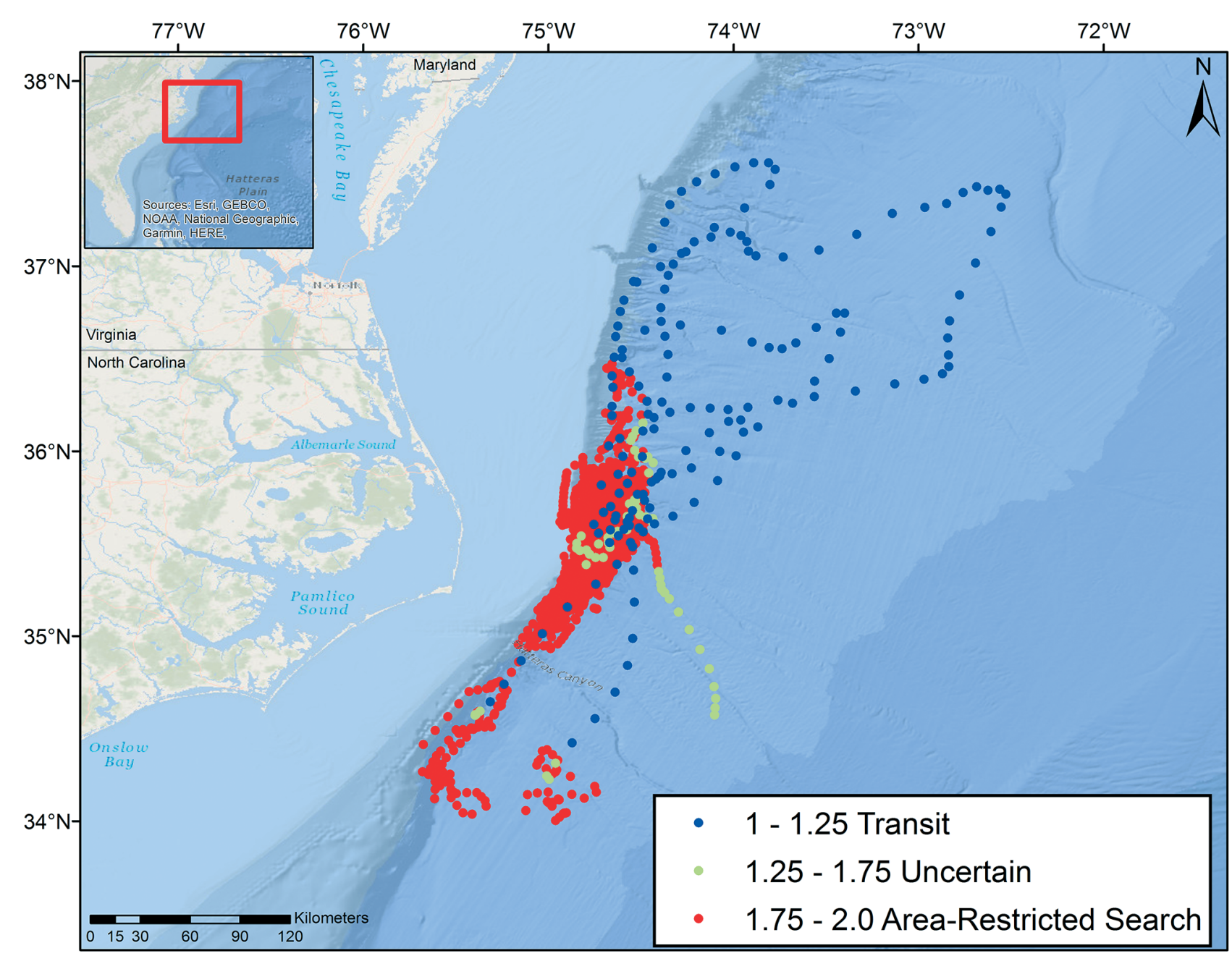

Fig. 2. Behavioral states estimated from a hierarchical switching state-space model ranging from 1 to 2 of Cuvier's beaked whales satellite-tagged off Cape Hatteras, North Carolina, USA, between 2014 and 2017 (n= 20; Table 1). Red indicates arearestricted search behavior, blue shows transit behavior, and green shows uncertain values

The home range for the sample population, estimated from the $95 \%$ isopleth, had an area of $7647 \mathrm{~km}^{2}$ (Fig. 3). Excluding the shortest-duration tag of only $2 \mathrm{~d}$ and 8 estimated locations, individual core use areas ranged from 71 to $872 \mathrm{~km}^{2}$ (median = $162 \mathrm{~km}^{2}$ ) while individual home range areas spanned 305-12 $697 \mathrm{~km}^{2}$ (median $=816 \mathrm{~km}^{2}$, Table 1, Fig. A1). Linear regression showed no evidence of association between either home range $(p=0.54$, $\left.\mathrm{R}^{2}=0.02\right)$ or core use area $\left(\mathrm{p}=0.53, \mathrm{R}^{2}=0.02\right)$ and individual track duration.

\subsection{Movement patterns}

Maximum net displacement had a sample median of $50 \mathrm{~km}$, ranging from $14 \mathrm{~km}$ for the shortestduration tag to $272 \mathrm{~km}$ for ZcTag057, which also had the largest core use and home range areas (Table 1, Fig. A1b). Linear regression indicated that increased transmission duration did not result in further displacement from the study area $(\mathrm{p}=$ $\left.0.4, R^{2}=0.04\right)$. For example, ZcTag047, with the second-longest duration of $67 \mathrm{~d}$, had a maximum net displacement of just $39 \mathrm{~km}$. Furthermore, every individual with $>100$ hSSSM-estimated locations remained in or returned to the Cape Hatteras study area at some point (Fig. 4). Potential movement pattern model fits demonstrated that individual Cuvier's beaked whales fell predominantly $(81 \%)$ into the 'home range' or resident movement pattern, with only 3 individuals (ZcTag041, ZcTag049, ZcTag050) demonstrating a nomadic movement curve. Model fits for migratory, dispersal, and mixed migratory movement tactics failed to converge for the sample population. 


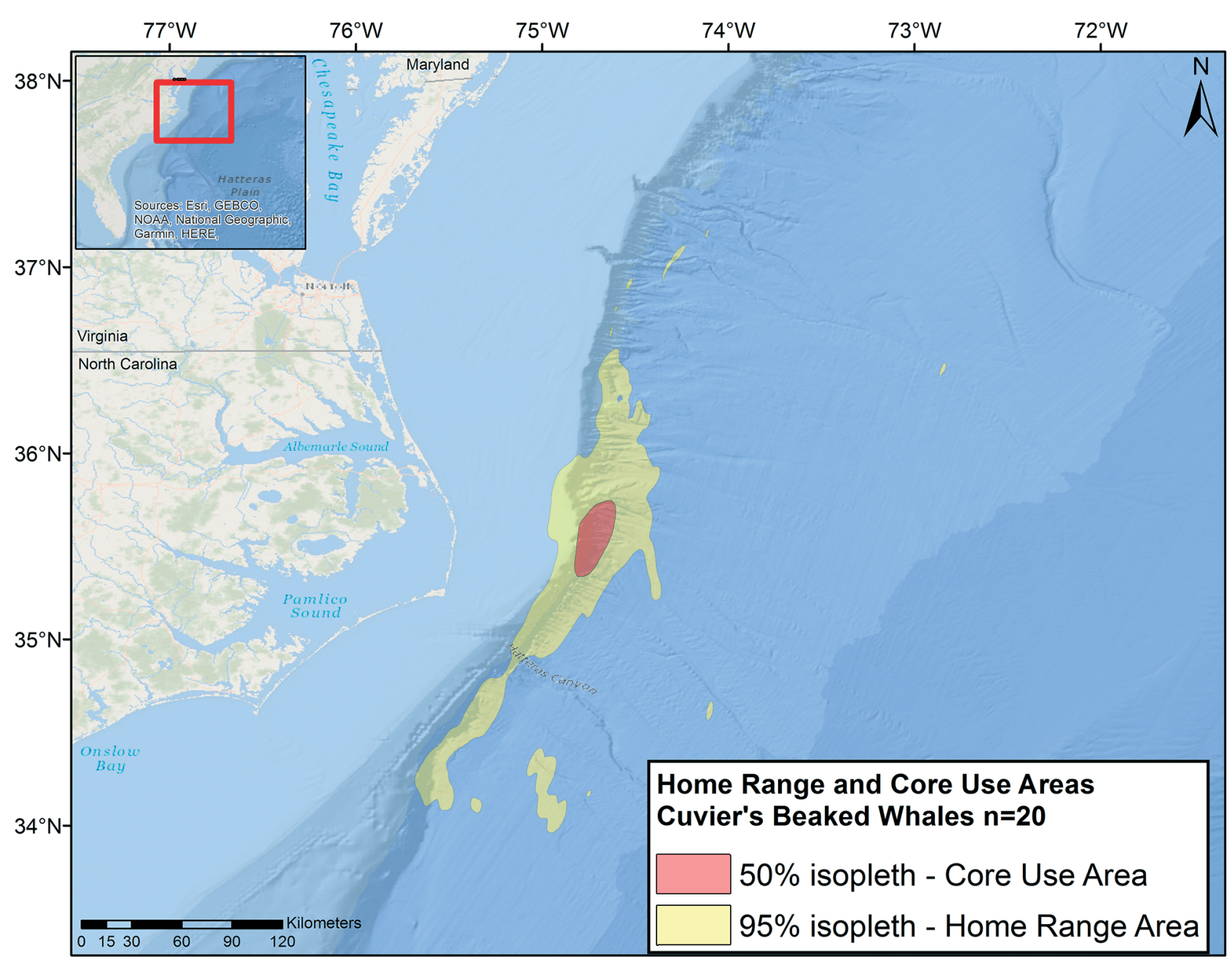

Fig. 3. Home range area (yellow) and core use area (red) for Cuvier's beaked whales satellite-tagged off Cape Hatteras, North Carolina, USA, between 2014 and $2017(n=20$; Table 1) generated from kernel density estimation

\section{DISCUSSION}

Our analysis demonstrates that Cuvier's beaked whales are resident to the slope waters off Cape Hatteras, North Carolina, USA, over periods of at least weeks to months. Tagged animals exhibited small, overlapping core use areas and little displacement from the region, tending to prefer relatively deep waters with high relief and warm sea surface temperatures close to the shelf break. ARS was the dominant behavior (96\% of locations) for all whales, and transit behavior did not occur at any point in the transmission duration for 15 of the 20 tagged individuals (Table 1).

We believe that the dominance of ARS displayed by our sample of tagged whales represents a resident population that is strongly linked to the bathymetric and oceanographic features of our study site. In addi- tion, the unusual diving patterns exhibited by this species, in which deep foraging dives are interspersed with shallower, non-foraging dives, may help to explain the preponderance of this behavioral mode. The function of these shallower 'bounce dives' is not fully understood, but it has been hypothesized that they may serve a variety of functions, including physiological recovery, rest, or providing an opportunity for social interactions (Tyack et al. 2006, Cioffi 2020). Unlike most other cetaceans, Cuvier's beaked whales spend very little time at the surface, so these functions must occur at depth and interspersed between foraging dives. We believe that this unusual behavioral pattern, together with a strong affinity to place, explains why most whales spent almost the entirety of their transmission periods in apparent ARS behavior. These results should not be interpreted as indicating that our tagged whales spent 


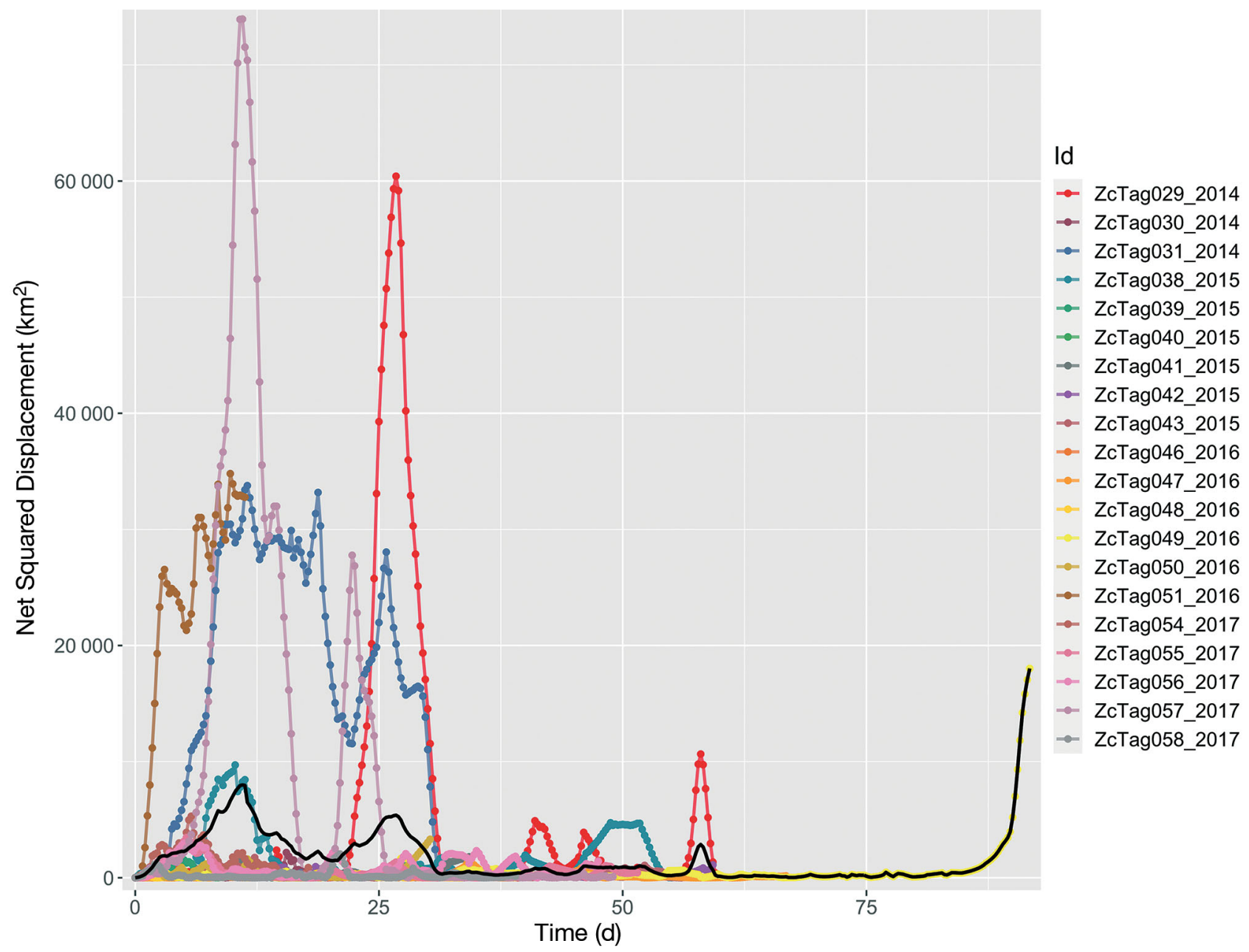

Fig. 4. Net squared displacement $\left(\mathrm{km}^{2}\right)$ over tag duration for Cuvier's beaked whales satellite-tagged off Cape Hatteras, North Carolina, USA, between 2014 and 2017 ( $n=20$; Table 1). Sample population mean represented by solid black line. Highest peak represents the maximum displacement, where values close to 0 represent the return of an individual to its initial location

$96 \%$ of their time foraging, however, as other essential behaviors, including resting and socializing, must be interspersed with foraging during these periods. We interpret our findings as indicating that our tagged whales engaged in a variety of behavioral modes within a fairly restricted area, at least during the summer months.

We identified a localized core use area for the tagged animals, as well as overlapping high use areas for individual whales. However, as the range for Cuvier's beaked whales is known to be expansive throughout deep slope waters of the western North Atlantic (Waring et al. 2001, 2016), it is still unclear what specific habitat characteristics of the area off Cape Hatteras attracts these animals in such high densities (Stanistreet et al. 2017, McLellan et al. 2018, Cioffi 2020, Waples \& Read 2020). Similar areas of relief and bathymetry are available both north and south of the core use area, but these outlying regions are not utilized as strongly. The confluence of the Gulf Stream and the Labrador Current often occurs near the core use area, producing productive fronts and eddies with which the species is believed to associate. These mesoscale features may create aggregations of prey, which ultimately determines the distribution of foraging whales (Laidre et al. 2004, Waring et al. 2016). Many animals use smaller home ranges than expected from observed mobility levels in environments with high prey availability (Börger et al. 2008, Acuña-Marrero et al. 2017, Couriot et al. 2018). Due to their ephemeral and patchy nature, however, prey-aggregating oceanographic features and processes are difficult to quantify over relevant spatiotemporal scales, even with the advancement of front-detecting algorithms applied to remotely sensed data (Etnoyer et al. 2006). Furthermore, we 
do not know whether these surface manifestations of meso-scale oceanographic conditions directly result in the aggregation of the meso- and bathypelagic prey on which the species relies (Moulins et al. 2007, West et al. 2017), but the effects of these processes warrant further study. Interestingly, we did not find any of the tagged animals that ventured into pelagic waters to directly associate with such aforementioned ephemeral fronts or eddies. Alternatively, fixed bathymetric features may be driving the consistent occurrence of Cuvier's beaked whales in the area, further supporting the residency of the sample population in the waters off Cape Hatteras.

Prey abundance, although difficult to measure in studies of deep-diving cetaceans, could help place the movements described here into an ecological context. However, very little is known about the abundance of meso- and bentho-pelagic squid and fish in the western North Atlantic, or how these prey species aggregate in relation to oceanographic variables. As such, static parameters such as depth and slope are often used as proxies for prey distribution (Palacios et al. 2013). However, static variables may not be the best substitutes for cetacean habitat at fine scales (Johnston et al. 2005). Instead, temporally dynamic covariates including mesoscale activity (upwelling, fronts, eddies, or currents) and their interactions with the physical features that can aggregate resources, particularly those below the surface, may be more directly applicable for identifying finescale deep-diving cetacean habitat (Abecassis et al. 2015, Briscoe et al. 2018). Incorporating telemetered dive data, while continuing to refine the definition of foraging vs. non-foraging dives in this species, could improve our ability to model the movements and spatial ecology of these whales, which spend very little time at the surface.

Individual beaked whale species may also occupy distinct ecological niches, and exhibit fine-scale habitat partitioning with other beaked whales and deep-diving odontocetes that occupy similar habitats, such as Gervais' beaked whales Mesoplodon europaeus, Blainville's beaked whales M. densirostris, short-finned pilot whales Globicephala macrorhynchus, and sperm whales Physeter macrocephalus (Schick et al. 2011, Stanistreet et al. 2017, Baird 2019). Individual Cuvier's beaked whales may have developed specialized foraging strategies within this small core use area off Cape Hatteras that are particularly efficient (Barlow et al. 2020), although their diet and foraging behavior is still poorly understood (MacLeod et al. 2003, West et al. 2017).
Most tagged individuals (81\%) fell under the 'resident', or home range, movement pattern, but 3 individuals demonstrated a more nomadic movement pattern. However, transmissions from these 3 whales (ZcTag041, ZcTag049, ZcTag050) ceased when they were at their maximum NSD (Fig. 4). NSD should increase linearly with time for nomadic movement (Harrison 2012), so such individuals were likely misclassified. For example, ZcTag049 had the longestduration tag (Table 1), and remained resident in the study area for nearly 3 mo before departing just before tag failure. The model fit for ZcTag049 was therefore more suited to a nomad than a resident. Every animal with more than 100 hSSSM-estimated relocations returned to its initial location at some point. Interestingly, 2 of the tagged animals never returned to their initial locations during tag transmission (ZcTag046 and ZcTag051). Despite constituting 2 of the shortest tag durations in the sample (16 and $11 \mathrm{~d}$, respectively, Table 1), it is conceivable that these individuals were not members of a population inhabiting the waters off Cape Hatteras, but rather part of a separate oceanic population that, on occasion, spatially overlaps with that of the animals tagged off Cape Hatteras, as has been observed in beaked whale populations in Hawai'i (Baird et al. 2011b, Baird 2019). However, we believe this to be unlikely, at least in the case of ZcTag046. Social network analyses link 12 of the 20 tagged whales (60\%) by association within a single cluster of animals (Cioffi 2020), including ZcTag046, which was seen together in the same group with ZcTag047, both at tagging as well as more than a year later (Waples \& Read 2020). Therefore, if ZcTag046 were to be a member of an oceanic population occasionally present in the region, the resident and oceanic populations must interact socially, evidence of which has not been observed in other regions (Baird et al. 2011b, Baird 2019). Similar reasoning applies to ZcTag051, which has never been re-sighted in the region nor linked by association to the main social network cluster. However, another individual sighted in the same group with ZcTag051 at tagging has twice been resighted in the area over 2 yr later, demonstrating site fidelity to the region (Waples \& Read 2020).

We were unable to assess the effects of seasonality in our study. Currently, our tagging efforts occur only between May and October, when favorable weather conditions allow field work. That limitation, along with typical duration of the tag transmissions, prevented us from collecting telemetry data for Cuvier's beaked whales between January and April. However, Stanistreet et al. (2017) found no evidence for 
seasonality in beaked whale acoustic detections along the western North Atlantic continental shelf break. Additionally, recent visual studies in the region have detected Cuvier's beaked whales at similar levels year-round, with little to no seasonal variation (McLellan et al. 2018).

Cuvier's beaked whales are a wide-ranging and cosmopolitan species, but high levels of site fidelity have been observed around the world (McSweeney et al. 2007, Moulins et al. 2007, Falcone et al. 2017, Reyes 2017, Baird 2019). The site fidelity and interannual residence of the animals in the Cape Hatteras region is further bolstered by recent literature demonstrating a year-round presence of Cuvier's beaked whales in the study area (Stanistreet et al. 2017, McLellan et al. 2018, Shearer et al. 2019). Ongoing photo-identification analyses from the region indicates a re-sighting rate of 0.30 for the species (Waples \& Read 2020). We have re-sighted over half of the satellite-tagged whales in this study in the Cape Hatteras area, and many other animals uniquely identified from photographs have been resighted across seasons and years (Waples \& Read 2020). Furthermore, most individual Cuvier's beaked whales sighted on more than 1 day $(83 \%)$ are linked by association in a single social network analysis cluster (Cioffi 2020). Taken together, this body of work demonstrates site fidelity to, and residency of Cuvier's beaked whales in, the continental slope waters off Cape Hatteras over several temporal scales, supporting our hypothesis.

The periodicity at which animals depart from and return to the Cape Hatteras study area varied between and within individuals and was difficult to quantify. Some animals demonstrated only a few forays away from the region, while other individuals departed and returned to the area several times throughout their tag transmission period. Such movements can also occur in response to disturbance. For example, Tyack et al. (2011) found that a satellitetagged Cuvier's beaked whale in the Bahamas moved 'several tens of $\mathrm{km}$ ' away from an area of a CEE, and took approximately $3 \mathrm{~d}$ to return, movements that were interpreted as a 'clear reaction to sonar.' Calculating such metrics for whales off Cape Hatteras, and working to distinguish between baseline and response behaviors, could help define and mitigate responses to CEEs with MFAS. However, further work is necessary to elucidate population-level patterns of departure from and return to the area.

Effective conservation relies on an accurate understanding of the space use and distribution of a species (Palacios et al. 2013, Winton et al. 2018). Here we have demonstrated that the continental slope waters off Cape Hatteras are a localized area of important habitat for Cuvier's beaked whales in which they dedicate significant time to ARS, suggesting foraging. The sample population of tagged whales remains in or close to the area over mediumterm time scales (weeks to months), and long-term site fidelity has been demonstrated through analysis of photographic records (Waples \& Read 2020).

Cuvier's beaked whales are particularly sensitive to anthropogenic disturbances, including MFAS, which has been proven to reduce fitness, negatively impact reproduction and survival, and cause injury and death in the species (Cox et al. 2006, DeRuiter et al. 2013, Baird 2019, Simonis et al. 2020). Two potential reactions to such acoustic disturbances observed in individual Cuvier's beaked whales are cessation of foraging and horizontal avoidance (DeRuiter et al. 2013). Repeated exposure to anthropogenic disturbances can negatively impact communication, energetics, and stress levels of an individual (Forney et al. 2017). The whales in our study demonstrated small core use areas and very little propensity for either dispersal or migration behavior, but continued acoustic disturbance may cause individuals to be forced out of their home ranges, thereby modifying their distributions over both space and time (Gomez et al. 2016). The Cuvier's beaked whale population off Cape Hatteras may not be able to successfully relocate or shift its limited distribution without considerable fitness costs. Our work represents one of the largest samples of telemetry data from any Cuvier's beaked whale population in the world, and the spatial ecology presented here is an important first step to better allow us to assess any future behavioral changes of this population in response to anthropogenic disturbance.

Acknowledgements. We are indebted to Will Cioffi, Nicola Quick, and Danielle Waples for their contributions to this work both in the field and the lab. The Naval Facilities Engineering Command Atlantic funded the field work and analyses. Satellite tagging was conducted under National Marine Fisheries Service Scientific Research Permit Nos. 17086, 20605, and 15330 issued to R.W.B. The Institutional Animal Care and Use Committee (IACUC) approved all research protocols.

\section{LITERATURE CITED}

Abecassis M, Polovina J, Baird RW, Copeland A and others (2015) Characterizing a foraging hotspot for short-finned pilot whales and Blainville's beaked whales located off the west side of Hawai'i Island by using tagging and oceanographic data. PLOS ONE 10:e0142628 
Acuña-Marrero D, Smith ANH, Hammerschlag N, Hearn A and others (2017) Residency and movement patterns of an apex predatory shark (Galeocerdo cuvier) at the Galapagos Marine Reserve. PLOS ONE 12:e0183669

Andrews RD, Pitman RL, Ballance LT (2008) Satellite tracking reveals distinct movement patterns for Type B and Type C killer whales in the southern Ross Sea, Antarctica. Polar Biol 31:1461-1468

Argos (2007-2016) User's manual. Collecte localisation satellites. https://www.argos-system.org/manual/

Bailey H, Mate BR, Palacios DM, Irvine L, Bograd SJ, Costa DP (2009) Behavioural estimation of blue whale movements in the Northeast Pacific from state-space model analysis of satellite tracks. Endang Species Res 10:93-106

Baird RW (2019) Behavior and ecology of not-so-social odontocetes: Cuvier's and Blainville's beaked whales. In: Würsig B (ed) Ethology and behavioral ecology of toothed whales and dolphins, the odontocetes. Springer, Cham, p 305-329

Baird RW, Webster DL, McSweeney DJ, Ligon AD, Schorr GS, Barlow J (2006) Diving behaviour of Cuvier's (Ziphius cavirostris) and Blainville's (Mesoplodon densirostris) beaked whales in Hawai'i. Can J Zool 84:1120-1128

* Baird RW, Schorr GS, Webster DL, McSweeney DJ, Hanson MB, Andrews RD (2010) Movements and habitat use of satellite-tagged false killer whales around the main Hawaiian Islands. Endang Species Res 10:107-121

Baird RW, Schorr GS, Webster DL, McSweeney DJ, Hanson MB, Andrews RD (2011a) Movements of two satellitetagged pygmy killer whales (Feresa attenuata) off the island of Hawai'i. Mar Mamm Sci 27:E332-E337

Baird RW, Schorr GS, Webster DL, Mahaffy SD, McSweeney DJ, Hanson MB, Andrews RD (2011b) Open-ocean movements of a satellite-tagged Blainville's beaked whale (Mesoplodon densirostris): evidence for an offshore population in Hawai'i? Aquat Mamm 37:506-511

Barlow J, Tyack PL, Johnson MP, Baird RW, Schorr GS, Andrews RD, Aguilar de Soto N (2013) Trackline and point detection probabilities for acoustic surveys of Cuvier's and Blainville's beaked whales. J Acoust Soc Am 134:2486-2496

* Barlow J, Schorr GS, Falcone EA, Moretti D (2020) Variation in dive behavior of Cuvier's beaked whale with seafloor depth, time-of-day, and lunar illumination. Mar Ecol Prog Ser 644:199-214

Börger L, Fryxell JM (2012) Quantifying individual differences in dispersal using net squared displacement. In: Clobert J, Baguette M, Benton T, Bullock J (eds) Dispersal and spatial evolutionary ecology, Oxford University Press, Oxford, p 222-230

Börger L, Dalziel BD, Fryxell JM (2008) Are there general mechanisms of animal home range behaviour? A review and prospects for future research. Ecol Lett 11:637-650

Briscoe DK, Fossette S, Scales KL, Hazen EL and others (2018) Characterizing habitat suitability for a centralplace forager in a dynamic marine environment. Ecol Evol 8:2788-2801

Bunnefeld N, Börger L, van Moorter B, Rolandsen CM, Dettki H, Solberg EJ, Ericsson G (2011) A model-driven approach to quantify migration patterns: individual, regional and yearly differences. J Anim Ecol 80:466-476

Chambault P, Roquet F, Benhamou S, Baudena A and others (2017) The Gulf Stream frontal system: a key oceanographic feature in the habitat selection of the leatherback turtle? Deep Sea Res I 123:35-47
Cioffi WR (2020) Social behavior of the Cuvier's beaked whale (Ziphius cavirostris) investigated by telemetry and photo-identification. PhD dissertation, Duke University, Durham, NC

* Couriot O, Hewison AJM, Saïd S, Cagnacci F and others (2018) Truly sedentary? The multi-range tactic as a response to resource heterogeneity and unpredictability in a large herbivore. Oecologia 187:47-60

Cox TM, Ragen TJ, Read AJ, Vos E and others (2006) Understanding the impacts of anthropogenic sound on beaked whales. J Cetacean Res Manag 7:177-187

* D'Amico A, Gisiner RC, Ketten DR, Hammock J, Johnson C, Tyack PL, Mead J (2009) Beaked whale strandings and naval exercises. Aquat Mamm 35:452-472

*De Solla SR, Bonduriansky R, Brooks RJ (1999) Eliminating autocorrelation reduces biological relevance of home range estimates. J Anim Ecol 68:221-234

*DeRuiter SL, Southall BL, Calambokidis J, Zimmer WMX and others (2013) First direct measurements of behavioural responses by Cuvier's beaked whales to mid-frequency active sonar. Biol Lett 9:20130223

* Duong T (2007) ks: Kernel density estimation and kernel discriminant analysis for multivariate data in R. J Stat Softw 21:1-16

*Doung T, Hazelton ML (2003) Plug-in bandwidth matrices for bivariate kernel density estimation. J Nonparametr Stat 15:17-30

* Duong T, Hazelton ML (2005) Cross-validation bandwidth matrices for multivariate kernel density estimation. Scand J Stat 32:485-506

* Etnoyer P, Canny D, Mate BR, Morgan LE, Ortega-Ortiz JG, Nichols WJ (2006) Sea-surface temperature gradients across blue whale and sea turtle foraging trajectories off the Baja California Peninsula, Mexico. Deep Sea Res II 53:340-358

Falcone EA, Schorr GS, Watwood SL, DeRuiter SL (2017) Diving behaviour of Cuvier's beaked whales exposed to two types of military sonar. R Soc Open Sci 4:170629

*Fieberg J (2007) Kernel density estimators of home range: smoothing and the autocorrelation red herring. Ecology 88:1059-1066

Forney KA, Southall BL, Slooten E, Dawson S, Read AJ, Baird RW, Brownell RL Jr (2017) Nowhere to go: noise impact assessments for marine mammal populations with high site fidelity. Endang Species Res 32:391-413

F Fortune SME, Ferguson SH, Trites AW, LeBlanc B, LeMay V, Hudson JM, Baumgartner MF (2020) Seasonal diving and foraging behaviour of Eastern Canada-West Greenland bowhead whales. Mar Ecol Prog Ser 643:197-217

* Gomez C, Lawson JW, Wright AJ, Buren AD, Tollit D, Lesage V (2016) A systematic review on the behavioural responses of wild marine mammals to noise: the disparity between science and policy. Can J Zool 94:801-819

*Hall P, Lahiri SN, Truong YK (1995) On bandwidth choice for density estimation with dependent data. Ann Stat 23: 2241-2263

Harrison AL (2012) A synthesis of marine predator migrations, distributions, species overlap, and use of Pacific Ocean Exclusive Economic Zones. PhD dissertation, University of California, Santa Cruz, CA

*Hauser DDW, Laidre KL, Suydam RS, Richard PR (2014) Population-specific home ranges and migration timing of Pacific Arctic beluga whales (Delphinapterus leucas). Polar Biol 37:1171-1183

* Hays GC, Ferreira LC, Sequeira AMM, Meekan MG and 
others (2016) Key questions in marine megafauna movement ecology. Trends Ecol Evol 31:463-475

Hildebrand JA (2009) Anthropogenic and natural sources of ambient noise in the ocean. Mar Ecol Prog Ser 395:5-20

*Hussey NE, Kessel ST, Aarestrup K, Cooke SJ and others (2015) Aquatic animal telemetry: a panoramic window into the underwater world. Science 348:1255642

Johnston DW, Westgate AJ, Read AJ (2005) Effects of finescale oceanographic features on the distribution and movements of harbour porpoises Phocoena phocoena in the Bay of Fundy. Mar Ecol Prog Ser 295:279-293

Jones MC, Marron JS, Sheather SJ (1996) A brief survey of bandwidth selection for density estimation. J Am Stat Assoc 91:401-407

Jonsen I (2016) Joint estimation over multiple individuals improves behavioural state inference from animal movement data. Sci Rep 6:20625

Jonsen ID, Myers RA, Flemming JM (2003) Meta-analysis of animal movement using state-space models. Ecology 84 : 3055-3063

Jonsen ID, Flemming JM, Myers RA (2005) Robust statespace modeling of animal movement data. Ecology 86: $2874-2880$

Jonsen ID, Myers RA, James MC (2007) Identifying leatherback turtle foraging behaviour from satellite telemetry using a switching state-space model. Mar Ecol Prog Ser 337:255-264

Kennedy AS, Zerbini AN, Rone BK, Clapham PJ (2014) Individual variation in movements of satellite-tracked humpback whales Megaptera novaeangliae in the eastern Aleutian Islands and Bering Sea. Endang Species Res 23: 187-195

Laidre KL, Heide-Jørgensen MP, Logdson ML, Hobbs RC and others (2004) Seasonal narwhal habitat associations in the high Arctic. Mar Biol 145:821-831

MacLeod CD, Santos MB, Pierce GJ (2003) Review of data on diets of beaked whales: evidence of niche separation and geographic segregation. J Mar Biol Assoc UK 83: 651-665

McLellan WA, McAlarney RJ, Cummings EW, Read AJ, Paxton CGM, Bell JT, Pabst DA (2018) Distribution and abundance of beaked whales (Family Ziphiidae) off Cape Hatteras, North Carolina, USA. Mar Mamm Sci 34:997-1017

McSweeney DJ, Baird RW, Mahaffy SD (2007) Site fidelity, associations, and movements of Cuvier's (Ziphius cavirostris) and Blainville's (Mesoplodon densirostris) beaked whales off the island of Hawai'i. Mar Mamm Sci 23: 666-687

Moors-Murphy HB (2014) Submarine canyons as important habitat for cetaceans, with special reference to the Gully: a review. Deep Sea Res II 104:6-19

Moulins A, Rosso M, Nani B, Würtz M (2007) Aspects of the distribution of Cuvier's beaked whale (Ziphius cavirostris) in relation to topographic features in the Pelagos Sanctuary (north-western Mediterranean Sea). J Mar Biol Assoc UK 87:177-186

Mullin KD, Fulling GL (2003) Abundance of cetaceans in the southern US North Atlantic Ocean during summer 1998. Fish Bull 101:603-613

* Palacios DM, Baumgartner MF, Laidre KL, Gregr EJ (2013) Beyond correlation: integrating environmentally and behaviourally mediated processes in models of marine mammal distributions. Endang Species Res 22:191-203

Papworth SK, Bunnefeld N, Slocombe K, Milner-Gulland EJ (2012) Movement ecology of human resource users: using net squared displacement, biased random bridges and resource utilization functions to quantify hunter and gatherer behaviour. Methods Ecol Evol 3:584-594

R Development Core Team (2018) R: a language and environment for statistical computing. R Foundation for Statistical Computing, Vienna

Reyes C (2017) Abundance estimate, survival and site fidelity patterns of Blainville's (Mesoplodon densirostris) and Cuvier's (Ziphius cavirostris) beaked whales off El Hierro (Canary Islands). MSc thesis, University of St Andrews

* Schick RS, Halpin PN, Read AJ, Urban DL and others (2011) Community structure in pelagic marine mammals at large spatial scales. Mar Ecol Prog Ser 434:165-181

* Schorr GS, Falcone EA, Moretti DJ, Andrews RD (2014) First long-term behavioral records from Cuvier's beaked whales (Ziphius cavirostris) reveal record-breaking dives. PLOS ONE 9:e92633

* Shearer JM, Quick NJ, Cioffi WR, Baird RW and others (2019) Diving behaviour of Cuvier's beaked whales (Ziphius cavirostris) off Cape Hatteras, North Carolina. R Soc Open Sci 6:181728

Simonis AE, Brownell RL Jr, Thayre BJ, Trickey JS, Oleson EM, Huntington R, Baumann-Pickering S (2020) Cooccurrence of beaked whale strandings and naval sonar in the Mariana Islands, Western Pacific. Proc R Soc B 287:20200070

Singh NJ, Börger L, Dettki H, Bunnefeld N, Ericsson G (2012) From migration to nomadism: movement variability in a northern ungulate across its latitudinal range. Ecol Appl 22:2007-2020

* Southall BL, Nowacek DP, Miller PJO, Tyack PL (2016) Experimental field studies to measure behavioral responses of cetaceans to sonar. Endang Species Res 31: 293-315

* Stanistreet JE, Nowacek DP, Baumann-Pickering S, Bell JT and others (2017) Using passive acoustic monitoring to document the distribution of beaked whale species in the western North Atlantic Ocean. Can J Fish Aquat Sci 74: 2098-2109

Thorne LH, Foley HJ, Baird RW, Webster DL, Swaim ZT, Read AJ (2017) Movement and foraging behavior of short-finned pilot whales in the Mid-Atlantic Bight: importance of bathymetric features and implications for management. Mar Ecol Prog Ser 584:245-257

* Tyack PL, Johnson M, Soto NA, Sturlese A, Madsen PT (2006) Extreme diving of beaked whales. J Exp Biol 209: 4238-4253

Tyack PL, Zimmer WMX, Moretti D, Southall BL and others (2011) Beaked whales respond to simulated and actual navy sonar. PLOS ONE 6:e17009

Walter WD, Onorato DP, Fischer JW (2015) Is there a single best estimator? Selection of home range estimators using area-under-the-curve. Mov Ecol 3:10

Waples DM, Read AJ (2020) Photo-identification analyses in the Cape Hatteras study area: 2019 annual progress report. Prepared for US Fleet Forces Command. Submitted to Naval Facilities Engineering Command Atlantic, Norfolk, Virginia, under Contract No N62470-15-D-8006, Task Order 19F4026 issued to HDR, Inc., Virginia Beach, VA

*Waring GT, Hamazaki T, Sheehan D, Wood G, Baker S (2001) Characterization of beaked whale (Ziphiidae) and sperm whale (Physeter macrocephalus) summer habitat in shelf-edge and deeper waters off the northeast US. Mar Mamm Sci 17:703-717 
Waring GT, Josephson E, Maze-Foley K, Rosel PE (eds) (2016) US Atlantic and Gulf of Mexico marine mammal stock assessments - 2015. NOAA Tech Memo NMFSNE-238

Weilgart LS (2007) The impacts of anthropogenic ocean noise on cetaceans and implications for management. Can J Zool 85:1091-1116

West KL, Walker WA, Baird RW, Mead JG, Collins PW
(2017) Diet of Cuvier's beaked whales Ziphius cavirostris from the North Pacific and a comparison with their diet world-wide. Mar Ecol Prog Ser 574:227-242

Winton MV, Fay G, Haas HL, Arendt M and others (2018) Estimating the distribution and relative density of satellite-tagged loggerhead sea turtles using geostatistical mixed effects models. Mar Ecol Prog Ser 586: $217-232$

Appendix. Individual-level plots depicting a single whale's estimated positions and trackline, behavioral state, core use area, home range area, and net-squared displacement throughout tag duration
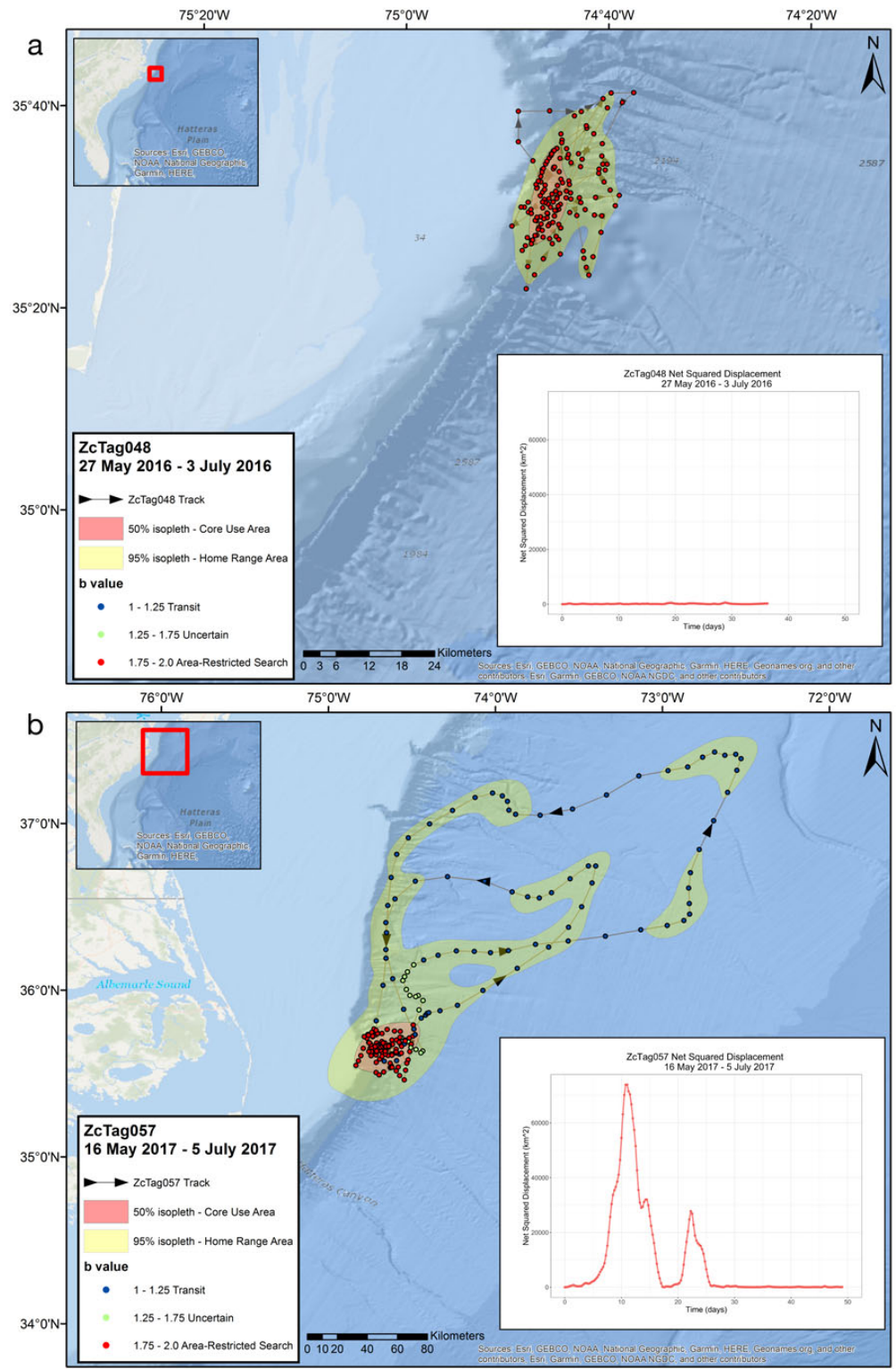

Fig. A1. Trackline of satellite-tagged Cuvier's beaked whale (a) ZcTag048 and (b) ZcTag057 off Cape Hatteras, North Carolina, USA, as estimated from a hierarchical switching state-space model, including behavioral state (b-values represented by colored dots) ranging from 1 (transit) to 2 (area-restricted search) at each estimated location. Also plotted are the core use area and the home range area. Inset graph in lower right corner demonstrates the net squared displacement throughout the tag duration - (a) 36.4 d for ZcTag048; (b) 49.4 d for ZcTag057 